\title{
MicroRNA-10a Influences Osteoblast Differentiation and Angiogenesis by Regulating $\beta$-Catenin Expression
}

\author{
Jun $\mathrm{Li}^{\mathrm{a}}$ Yongqing Zhang ${ }^{\mathrm{b}}$ Qingxia Zhaoc Jianghua Wang ${ }^{c} \quad$ Xijing He$^{\mathrm{d}}$ \\ ${ }^{a}$ Department of Emergency Surgery, Third Hospital of Xi'an Jiaotong University and People's Hospital \\ of Shaanxi Province, Xi'an, bepartment of Pneumology, Third Hospital of Xi'an Jiaotong University \\ and People's Hospital of Shaanxi Province, Xi'an, 'Department of Operating Theatre, Third Hospital of \\ Xi'an Jiaotong University and People's Hospital of Shaanxi Province, Xi'an, dDepartment of Orthopedics, \\ Second Hospital of Xi'an Jiaotong University, Xi'an, China
}

\section{Key Words}

MicroRNA-10a • Osteoblast differentiation • Angiogenesis • $\beta$-catenin • Bone regeneration

\begin{abstract}
Background/Aims: Elucidation of the molecular mechanisms governing osteoblast differentiation and angiogenesis are of great importance for improving the treatment of bone-related diseases. In this study, we examined the role of microRNA (miR)-10a in the differentiation of MC3T3-E1 cells and pro angiogenic activity of mouse umbilical vein endothelial cells (MUVECs). Methods: The murine pre-osteoblast cell line MC3T3-E1 and MUVECs were used in the experiment. After transfected with miR-10a mimics or inhibitors, with or without LiCl pretreatment, the miR-10a, ALP, Runx2, Osx, OC and DIx5 expression were assessed by RT-PCR. MC3T3-E1 cells were cultured with BMP2 to differentiate into bone cells, osteogenic differentiation of MC3T3-E1 cells were detected by ALP and ARS staining. Cell viability were analyzed by MTT and the protein expression of $\beta$-catenin, LEF1, cyclinD1, MMP2, and VEGF were detected by Western blotting; VEGF and VE-cadherin release were assessed by ELISA, and the migration of MUVECs, as well as tube formation were also detected. Results: MiR-10a expression was obviously down-regulated during osteogenic differentiation. Overexpression of miR-10a inhibited osteogenic differentiation of MC3T3-E1 cells, effectively decreasing MUVECs proliferation, migration, VEGF expression, VE-cadherin concentrations, and tube formation in vitro, whereas miR-10a silence enhanced those processes. Further mechanism assays demonstrated that overexpression of miR-10a reduced the $\beta$-catenin at both protein and transcription level, while pretreatment with Wnt signaling activator Licl partially attenuated the suppression effects of miR-10a overexpression on osteoblast differentiation and angiogenesis. Conclusion: Our findings imply that miR-10a plays a suppressive role in osteoblast differentiation of MC3T3-E1 cells and pro angiogenic activity of MUVECs by regulating the $\beta$-catenin expression, representing a novel and potential therapeutic target for the treatment of bone regeneration-related diseases.

J. Li and Y. Zhang contributed equally to this work.

Xijing He

Department of Orthopedics, Second Hospital of Xi'an Jiaotong University, No 157, Xiwu Road, Xi'an 710004, (China)

Tel. +86139092 66195, Fax +86 029876 79601, E-Mail xijinghejt@163.com
\end{abstract}

KARGER 125 


\section{Cellular Physiology Cell Physiol Biochem 2015;37:2194-2208 \begin{tabular}{ll|l} 
and Biochemistry & DOI: 10.1159/000438576 & $\begin{array}{l}\text { O) } 2015 \text { The Author(s). Published by S. Karger AG, Basel } \\
\text { www.karger.com/cpb }\end{array}$ \\
\cline { 2 - 3 }
\end{tabular} \\ Li et al.: MicroRNA-10a Regulates Osteoblast Differentiation and Angiogenesis}

\section{Introduction}

Bone defects caused by traumas, congenital malformations or diseases cause enormous social and economic burdens, which seriously affect people's quality of life worldwide [1]. The main issue in the treatment and prevention of these diseases remains how to promote osteogenesis. Among the many factors of bone regeneration, osteoblast differentiation and angiogenesis play the most important roles [2, 3]. Reports show that inhibiting osteoblast differentiation significantly induced bone loss in a mouse model [4]. Furthermore, angiogenesis, which provides nutrition during skeletal development, also has an important part in bone formation [5]. Thus, elucidation of the molecular mechanisms governing osteoblast differentiation and angiogenesis are of great importance for improving the treatment of bone-related diseases. There are a wide variety of stimuli and signal pathways taking part in the process of bone regeneration. In terms of skeletal homeostasis and bone repair, the Wnt pathway is among the most attractive targets for such therapeutic interventions. There is now a substantial literature supporting the role of Wnt signaling in skeletogenesis and a growing appreciation for the functions of Wnt in regulating stem cell and skeletal cell behaviors [6, 7]. Reports show that Wnt signals regulate bone mass by perpetuating the self-renewal and proliferation of stem cells and inducing differentiation of osteoprogenitor cells $[8,9]$. Therefore, targeting the Wnt pathway may provide novel insights into the mechanisms underlying bone formation.

MicroRNAs (miRNAs) are a family of non-coding RNAs that are 18-22 nucleotides in length and inhibit target gene expression by inducing Mrna degradation or by blocking protein translation [10]. Recently, several miRNAs have been reported by many researchers to regulate skeletal homeostasis and osteoblastogenes, either positively or negatively, through multiple signaling pathways $[11,12]$. For example, several miRNAs were shown to influence stem cell differentiation into osteocytes, to repress osteogenic differentiation of adipose-derived stromal cells [13], to mediate BMP-2 dependent osteoblast proliferation and differentiation [14], or to contribute to angiogenesis [15]. Among the miRNAs, miR10a has been shown to be involved in many pathological processes, such as tumor cell proliferation and migration, as well as for angiogenic processes [16]. Recently, numerous studies characterize miR-10a as a biomarker for injury, such as kidney injury [17] and cardiac injury [18]. However, its effect and the underlying mechanism involved in the progression of bone regeneration remains unclear.

Here, we demonstrated that miR-10a was down-regulated in BMP2-induced osteoblast differentiation of MC3T3-E1 cells. Its roles in pro angiogenic activity were investigated through the use of MUVECs. Furthermore, the functional pathway in which miR-10a participated was also explored.

\section{Materials and Methods}

\section{Antibodies and reagents}

All substances were purchased from Gibco (Grand Island, NY), if not otherwise mentioned. A-minimal essential medium (AMEM) and RPMI 1640 medium were bought from Abcam (Cambridge, MA). Licl (Wnt/ $\beta$-catenin signaling pathway activator) was bought from Calbiochem (San Diego, CA). Rabbit anti-LEF1, ALP, $\beta$-catenin, GSK3- $\beta$, cyclin D1, MMP2 and VEGF polyclonal antibodies were from Santa Cruz Biotechnology (Santa Cruz, CA). Anti- $\beta$-catenin and $\beta$-actin antibodies were bought from Sigma (St. Louis, MO). HRPconjugated goat anti-mouse and anti-rabbit antibodies were from Abcam (Cambridge, MA).

\section{Cell lines and cell culture}

The murine pre-osteoblast cell line MC3T3-E1 and mouse umbilical vein endothelial cells (MUVECs) were obtained from CHI Scientific, Inc. (Massachusetts, USA) and were cultured according to the established protocols. Briefly, MC3T3-E1 cells were cultured in a proliferation medium containing the a-minimal essential medium (Amem) supplemented with 10\% fetal bovine serum (FBS), 2 Mm of L-glutamate, 100 


\section{Cellular Physiology Cell Physiol Biochem 2015;37:2194-2208 \begin{tabular}{ll|l}
\cline { 2 - 2 } DOI: 10.1159/000438576 & () 2015 The Author(s). Published by S. Karger AG, Basel
\end{tabular} and Biochemistry Published online: November 27, 2015 www.karger.com/cpb \\ Li et al.: MicroRNA-10a Regulates Osteoblast Differentiation and Angiogenesis}

$\mathrm{U} / \mathrm{ml}$ of penicillin, and $100 \mu \mathrm{g} / \mathrm{ml}$ of streptomycin. Cells at passages 16 were used for this study. MUVECs were grown in RPMI 1640 medium containing vascular endothelial growth factor (VEGF), heparin, $20 \%$ fetal bovine serum (FBS) (Atlanta Biologicals), 1\% ascorbic acid $100 \mathrm{U} / \mathrm{ml}$ penicillin, and $100 \mathrm{mg} /$ $\mathrm{ml}$ streptomycin. The fourth to sixth passage MUVECs in actively growing conditions were used for the experiments. All cells were cultured at $37^{\circ} \mathrm{C}$ in an incubator (Life Technologies, Baltimore, MD) containing $5 \% \mathrm{CO}_{2}$. Osteoblastic differentiation was induced by the addition of $300 \mathrm{ng} / \mathrm{ml} \mathrm{BMP2}$ for $7 \mathrm{~d}$ [19].

\section{Oligonucleotide and siRNA transfection}

Cells were seeded into six-well plates, and were then transfected with miR-10a mimics, miR-10a inhibitors, or miR controls (50 nM, GenePharma) using Lipofectamine. Briefly, the MC3T3-E1/MUVEC cells were seeded at a concentration of $2 \times 10^{7} /$ well. Then, a miR-10a mimic/inhibitor was added when the cells reached about $60 \%$ confluence. The cells were incubated with $40 \mathrm{Nm}$ mimic/inhibitors or their matched negative controls (mimic-nc/inhibitor-nc) for $48 \mathrm{~h}$. Then, the RT-PCR analysis was performed to evaluate the transfected effect.

GSK3- $\beta$ siRNA (Sigma-Aldrich) transfection was performed according to the manufacture's instruction. Briefly, $1 \mu \mathrm{g}$ of vectorwas incubated with $50 \mu \mathrm{l}$ of serum-free medium for 5 min (Solution A), and $2 \mu \mathrm{l}$ of Lipofectamine 2000 was incubated with serum-free medium for 5 min (Solution B). Solution A was mixed with solution $\mathrm{B}$, and incubated for $20 \mathrm{~min}$. After incubation, cells were added to the mixture. Cells were then harvested at 48 hours after transfection for further analysis. The efficiency of GSK3- $\beta$ siRNA was confirmed by Western blotting analysis.

\section{$\beta$-catenin Plasmid Construction and Cell Transfection}

Total RNA was isolated from experimental cells using TRIzol reagent (Invitrogen, Carlsbad, CA, USA), based on the manufacturer's instructions. The cDNA was synthesized by reverse transcription of total RNA, using the PrimeScript RT reagent kit (Takara, Dalian, China) with oligo-dT primers, according to the manufacturer's protocol. Then, the open reading frame of DDAH1 cDNA was cloned and inserted into the pcDNA3.1 vector (Invitrogen, Carlsbad, CA), namely pcDNA3.1- $\beta$-catenin expression vector, The pcDNA3.1 vector alone transfected cells were used as negative control. For cell transfection, cells were cultured to $60 \%$ confluence, cell transfection was performed using the FuGENE HD transfection reagent (Roche, Indianapolis, IN) methods as suggested by the manufacturer.

\section{3-(4, 5-Dimethylthiazol-2-yl)-2, 5-diphenyltetrazoliumbromide (MTT) assay analysis}

MC3T3-E1 cells and MUVECs viability were determined by MTT assay. The cells transfected with miR$10 \mathrm{a}$ mimic/inhibitor and the corresponding negative control were planted in the 96-well plates and cultured under regular conditions until they reached $80 \%$ confluence. Then, the culture medium was discarded and fresh medium containing MTT (5 mg/ml in PBS, $150 \mu \mathrm{l} /$ well, Sangon, Shanghai, China) was added followed by incubation with cells for an additional four hours. Then, $150 \mu \mathrm{l}$ of DMSO (Sigma) was added per well and was shaken gently for $10 \mathrm{~min}$ to dissolve the formazan. Absorbance at $570 \mathrm{~nm}$ was determined using an ELISA reader. Each cell's viability assay was performed in quadruplicate and repeated three times and the cell viability was expressed as percent-ages of the value of normal cells.

\section{Transwell migration assay}

The BioCoat migration chamber was purchased from BD Biosciences (Bedford, MA). Transwell migration assays were performed with 8 - $\mu$ m porous chambers according to the manufacturer's instructions. A total of $1 \times 10^{6}$ MUVECs in $0.5 \mathrm{ml}$ culture medium were implanted into the upper chamber. The bottom well contained $0.6 \mathrm{ml}$ of Dulbecco's modified Eagle's medium with $10 \%$ fetal bovine serum. After culturing for $24 \mathrm{~h}$, the cells in the upper and lower chambers were stained with $0.4 \%$ trypan blue, followed by airdrying; the membrane was thenstained with crystal violet. The number of migrating cells was then counted using a microscope under five fields $(\times 200)$.

\section{$R T-P C R$}

Total RNA was extracted using Unizol Reagentaccording to the manufacturer's instructions (Invitrogen, Carlsbad, CA, USA). About $5 \mu \mathrm{g}$ of RNA from each sample was used as a template for Cdna synthesis with a reverse transcription kit (Fermentas, St. Leon-Rot, Germany). An equal volume of Crna product was used in 


\section{Cellular Physiology Cell Physiol Biochem 2015;37:2194-2208 \begin{tabular}{ll|l}
\cline { 2 - 2 } and & DOI: 10.1159/000438576 & $\begin{array}{l}\text { C 2015 The Author(s). Published by S. Karger AG, Basel } \\
\text { www.karger.com/cpb }\end{array}$ \\
\hline
\end{tabular} \\ Li et al.: MicroRNA-10a Regulates Osteoblast Differentiation and Angiogenesis}

Table 1. Sequences of primers

\begin{tabular}{lll}
\hline Targeted gene & Sense primer $\left(5^{\prime}-\right.$-3' $^{\prime}$ ) & Antisense primer (5'-3') \\
\hline ALP & CCG ATG GCA CAC CTG CTT & GAG GCA TAC GCC ATC ACA TG \\
OC & AGC AGC TTG GCC CAG ACC TA & TAG CGC CGG AGT CTG TTC ACT AC \\
Runx2 & CAC TGG CGG TGC AAC AAG A & TTT CAT AAC AGC GGA GGC ATT TC \\
OSX & CCT CTG CGG GAC TCA ACA AC & TGC CTG GAC CTG GTG AGA TG \\
Dlx5 & GCC CCT ACC ACC AGT ACG & TCA CCA TCC TCA CCT CTG \\
VE-Cadherin & ACG GAC AAG ATC AGC TCC TC & TCT CTT CAT CGA TGT GCA TT \\
LRP5 & CGT GAT TGC CGA TCT C & TTC CGG CCG CTA GTC TTG T \\
cyclin D1 & AAC AGA TTG AAG CCC TTC T & ATC TCA GTG GTA TTT GTG A \\
VEGF & GAA GTC CCA TGA AGT GAT CCA G & TCA CCG CCT TGG CTT GTC A \\
$\beta$-catenin & ATC ACT GAG CCT GCC ATC TG & GTT GCC ACG CCT TCA TTC C-3 \\
GSK3- $\beta$ & CCT GGT GCT GGA CTA TGT & CAA GAG GTT CTG TGG TTT AA \\
$\beta$-actin & AGG AGC AAT GAT CTT GAT CTT & TGC CAA CAC AGT GCT GTC T \\
miR-10a & ACC CTG TAG ATC CGA ATT TGT G & \\
U6 snRNA & TGG CCC CTG CGC AAG GAT G & \\
\hline
\end{tabular}

the PCR. The primers used for amplification are listed in Table 1. The PCR conditions comprised 35 cycles of denaturation at $94^{\circ} \mathrm{C}$ for $30 \mathrm{~s}$, annealing at $54^{\circ} \mathrm{C}$ for $30 \mathrm{~s}$, and polymerization at $72^{\circ} \mathrm{C}$ for $30 \mathrm{~s}$. Aliquots of the PCR products were electrophoresed on $1.5 \%$ agarose gels, and PCR fragments were visualized by ethidium bromide staining. Real-time PCR experiments for each gene were performed on three separate occasions. B-actin and U6 SnRNA were used for internal control of Mrna or miRNA, respectively (Table 1).

\section{Western blotting}

Expressions of LEF1, ALP, $\beta$-catenin, cyclin D1, MMP2 and VEGF were analyzed by Western blotting using commercially available antibodies. Cells were lysed in cell lysis buffer (Beyotime, Haimen, China) and the protein concentration was measured using the Bradford method. A total of 20-30 $\mu \mathrm{g}$ of protein was loaded on $12 \%$ sodium-dodecyl sulfate-polyacrylamide gel electrophoresis (SDS-PAGE) gels and blotted onto polyvinylidene fluoride (PVDF) membranes. The membranes were blocked by $2.5 \%$ nonfat milk for 1 $\mathrm{h}$ at $37^{\circ} \mathrm{C}$, and were then incubated with primary antibodies against LEF1 (1:2000), ALP (1:1000), cyclin D1 (1:1000), MMP2 (1:1000), VEGF (1:1000), $\beta$-catenin (1:1000), GSK3- $\beta(1: 1000)$ and $\beta$-actin $(1: 2000)$ at $4^{\circ} \mathrm{C}$ overnight. After incubation with HRP-conjugated secondary antibody for $1 \mathrm{~h}$ at room temperature, protein bands were visualized using an enhanced chemiluminescence detection system. Densitometry values were normalized to levels of $\beta$-actin and the control lane in each blot.

Alkaline phosphatase staining (ALP) and alizarin red staining (ARS)

ALP staining was used to evaluate the osteoblast phenotype. The ALP staining was performed at $7 \mathrm{~d}$ after drug treatment using an ALP staining kit (Nanjing Jiancheng Bioengineering Institute, China) according to the manufacturer's instructions. ARS was performed at $12 \mathrm{~d}$ to detect the osteoblast calcification after BMP2 and miR-10a mimic/inhibitor pretreatment. Cells in 24-well plates were washed with PBS, fixed in 95\% ethanol for $10 \mathrm{~min}$, washed with distilled water, and then were stained by alizarin red solution $(1 \mathrm{~g}$ Tris and $0.1 \mathrm{~g}$ alizarin red (Bio Basic Inc., Canada) in $100 \mathrm{ml}$ ultrapure water, adjusting the $\mathrm{Ph}$ to 8.3 by Hcl for 30 min at $37^{\circ} \mathrm{C}$. After being washed with distilled water twice, the cells were photographed.

\section{Tube formation assay}

To assess the ability of MUVECs to integrate in the vascular structure, a Matrigel tube formation assay was performed. A 48-well culture plate was coated with Matrigel plus $100 \mathrm{ng} / \mathrm{ml}$ VEGF. The MUVECs cultured with the test compounds were seeded in the Matrigel-coated plate at concentrations of $5 \times 10^{4}$ cells per well. After $24 \mathrm{~h}$, the vascular structural tube formed by MUVECs was fixed and stained with the Diff-Quik $^{\circledR}$ staining set (DADE BEHRING, Inc., Newark, DE), according to the manufacturer's instructions. After washing three times with PBS, the average length of the tube branches in four areas of each sample was assessed under an inverted light microscope. 


\section{Cellular Physiology Cell Physiol Biochem 2015;37:2194-2208 \begin{tabular}{ll|l} 
and Biochemistry & $\begin{array}{l}\text { DOI: 10.1159/000438576 } \\
\text { Published online: November 27, } 2015\end{array}$ & $\begin{array}{l}\text { C } 2015 \text { The Author(s). Published by S. Karger AG, Base } \\
\text { www.karger.com/cpb }\end{array}$ \\
\hline
\end{tabular} \\ Li et al.: MicroRNA-10a Regulates Osteoblast Differentiation and Angiogenesis}

\section{ELISA analysis}

The levels of VEGF and VE-cadherin concentrations in the culture medium were analyzed using a commercially available enzyme linked immunosorbent assay (ELISA; Yanjin Biotechnology Co., Shanghai, China) according to the manufacturer's procedure; the absorbance was taken at $450 \mathrm{~nm}$ using a microplate reader (Biorad, Hercules, USA). All of the samples were analyzed in duplicate.

\section{Statistical analysis}

The quantitative data was expressed as mean \pm SD. Statistical analysis was carried out using a one-way analysis of variance (ANOVA) followed by a Bonferroni test for multiple groups, or a Student's t-test between two groups (using SPSS 13.0 software; SPSS Inc., Chicago, USA). Differences with a p value less than 0.05 were regarded as statistically significant.

\section{Results}

MiR-10a inhibits BMP2-induced differentiation of MC3T3-E1 cells

To gain an insight into the role of miR-10a in osteoblastic differentiation, we first examined the osteogenic-related proteins, alkaline phosphatase (ALP), runt-related transcription factor 2 (Runx2), as well as miR-10a mRNA expression during the osteoblast differentiation over 7 days (cultured with 300ng/ml BMP2). The results showed a timedependent increase of ALP and Runx2 expression, and a significantly decrease of miR-10a mRNA expression. As shown in Fig. 1A, the expression of ALP and Runx2 began rise at 48 $\mathrm{h}$ and reach a peak at the $7^{\text {th }}$ day. While miR-10a was significantly decreased by more than $50 \%$ at the $7^{\text {th }}$ day, compared with that of untreated control MC3T3-E1 cells, suggesting that miR-10a might play a critical role in osteoblastic differentiation.

To further investigate the role of miR-10a during osteoblast differentiation, we stably transfected MC3T3-E1 cells with miR-10a mimics or inhibitors and respective negative control to reinforce the effect of miRNAs. Afterwards, the osteogenesis ability was examined. According to the RT-PCR analysis, a 3-fold increase of mature miR-10a expression was shown in MC3T3-E1 cells $48 \mathrm{~h}$ post-transfection of miR-10a mimics, and a 2-fold decrease was found after transfection of the miR-10a inhibitor (Fig. 1B). MiR-10a target, PTEN was used to control whether the mimic and the inhibitor is working. Results show that the oligonucleotide was successfully transfected (Fig. 1C). The results of the MTT assay exhibited an approximate $50 \%$ decrease in cell viability after miR-10a mimic transfection, but more than 2-fold increase in MC3T3-E1 cells after miR-10a inhibitor transfection compared to the controls (Fig. 1D). The osteogenic induction was conducted at d0 after transfection. After induction by BMP2 for $7 \mathrm{~d}$, ALP staining showed a significantly lessened difference in the miR-10a mimic group compared with the mimic-negative control (mimic-nc) group, whereas, after inhibition of miR-10a, the outcome was totally inversed (Fig. 1E upper). The alizarin red staining at $\mathrm{d} 12$ showed the same tendency at the matrix mineralization level (Fig. $1 \mathrm{E}$ lower), the cells without BMP2 treatment were also assessed at the same time point as controls. Results show that without BMP2 treatment, miR-10a overexpression also inhibits the spontaneous differentiation of MC3T3-E1 cells, while miR-10a silencing promoted the spontaneous differentiation of MC3T3-E1 cells. However, this changes is inconspicuous compare with the cells treated with BMP2. Key osteogenic-specific genes' (ALP, Runx2, osterix (Osx), osteocalcin (OC), and distal-less homeobox5 (DLX5)) Mrna expression was examined by RT-PCR after $48 \mathrm{~h}$ induction. The results showed that the osteoblast differentiationrelated genes' (ALP, Runx2, OSX, OC, and DLX5) Mrna expression were significantly downregulated after miR-10a mimic transfection, but up-regulated after the inhibition of miR-10a in MC3T3-E1 cells (Fig. 1F and G). Therefore, these results suggested that overexpression of miR-10a may result in osteogenesis inhibition, while down-regulation of miR-10a promoted osteogenesis. 


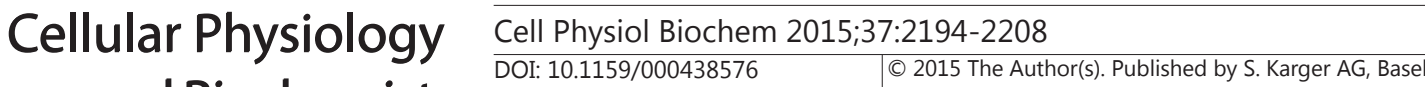 and Biochemistry Published online: November 27, 2015 www.karger.com/cpb

A

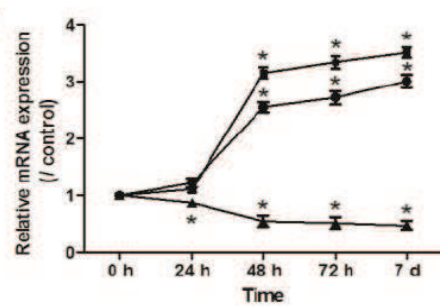

B

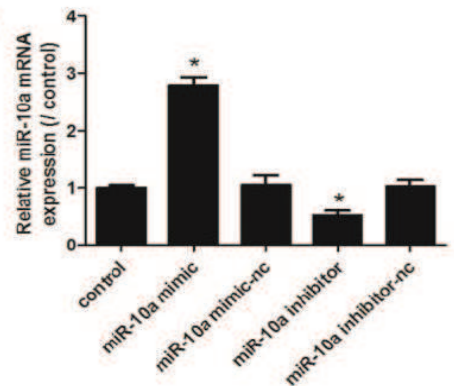

C

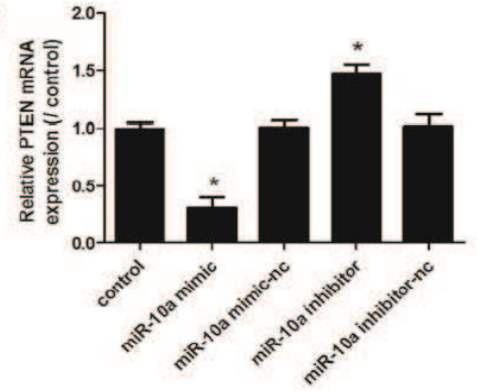

D

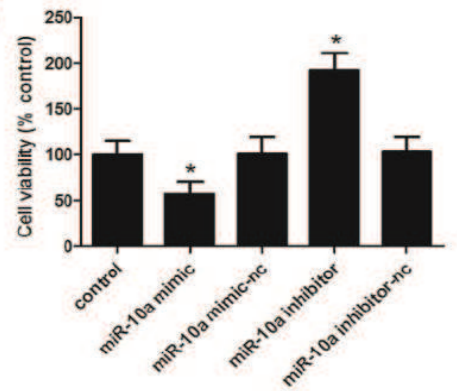

E

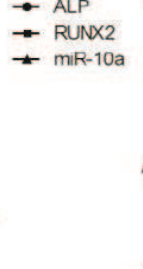

ARS
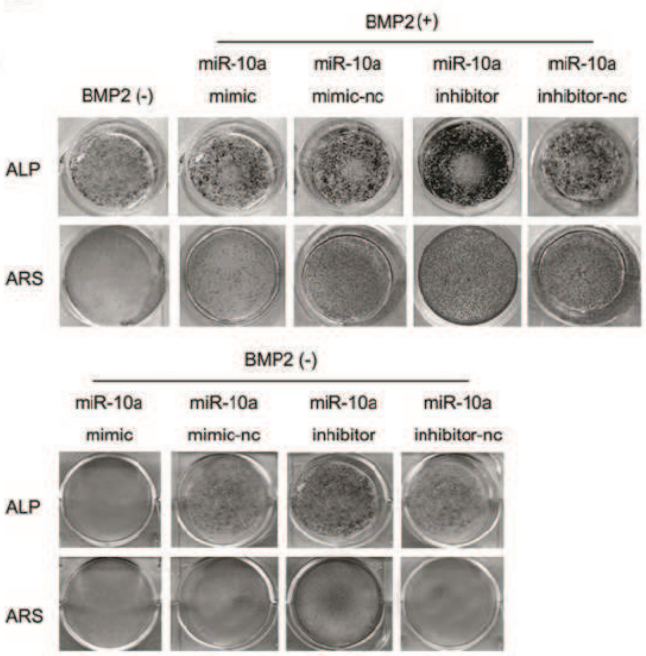

F

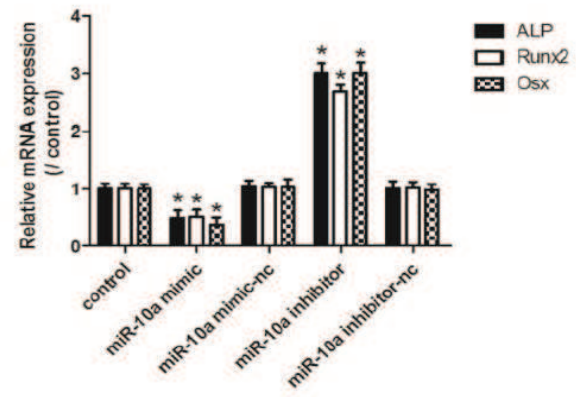

G

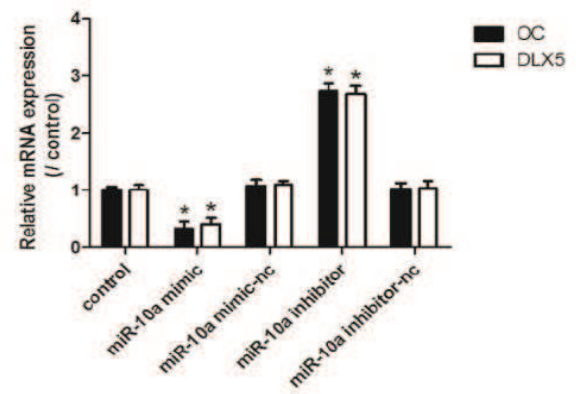

Fig. 1. MiR-10a inhibits BMP2-induced MC3T3-E1 osteogenic differentiation. The MC3T3-E1 cells was treated with BMP2 $(300 \mathrm{ng} / \mathrm{ml})$ for 7 days. The mRNA level of ALP, Runx2 and miR-10a were measured by RTPCR (A). After transfecting with a miR-10a mimic/inhibitor or mimic/inhibitor-negative control (nc) for 48 $\mathrm{h}$, the mRNA expression of miR-10a was analyzed (B). PTEN, a known miR-10a target, was used to control whether the mimic and the inhibitor is working (C). MC3T3-E1 cell viability was assessed by MTT (D). The osteoblast phenotype was evaluated by ALP staining and the osteoblast calcification was detected by ARS staining (E). Osteoblast differentiation-related genes, ALP, Runx2, OSX (F), and OC, DLX5 (G), were analyzed using RT-PCR. $\beta$-actin and U6 SnRNA were used as a loading control. Data are presented as mean \pm SD. The * symbol indicates differences from their respective controls, at $\mathrm{p}<0.05$.

MiR-10a suppresses cell viability, migration and tube formation in MUVECs

To determine whether miR-10a could influence angiogenesis, miR-10a mimics and inhibitors were individually transfected into MUVECs and their effects were assessed by 


\section{\begin{tabular}{ll} 
Cellular Physiology & Cell Physiol Biochem 2015;37:2194-2208 \\
\cline { 2 - 2 } DOI: 10.1159/000438576 & ( 2015 The Author(s). Published by S. Karger AG, Basel
\end{tabular} and Biochemistry Published online: November 27, 2015 www.karger.com/cpb

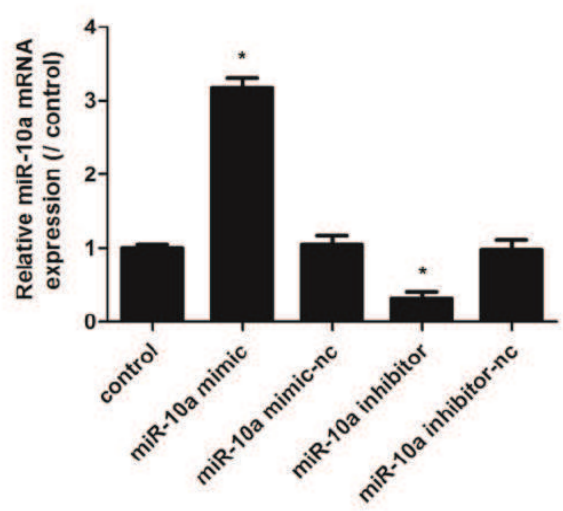

C

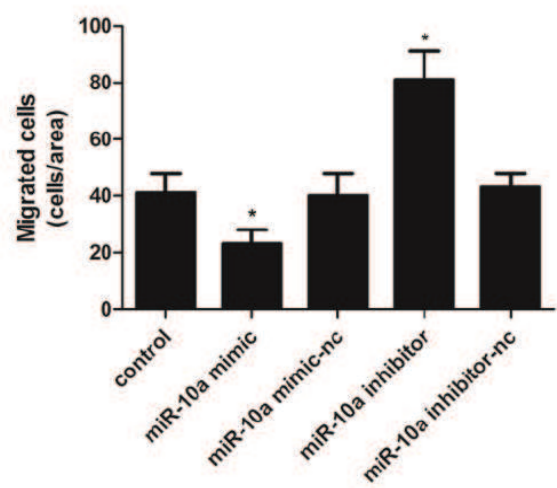

$E$

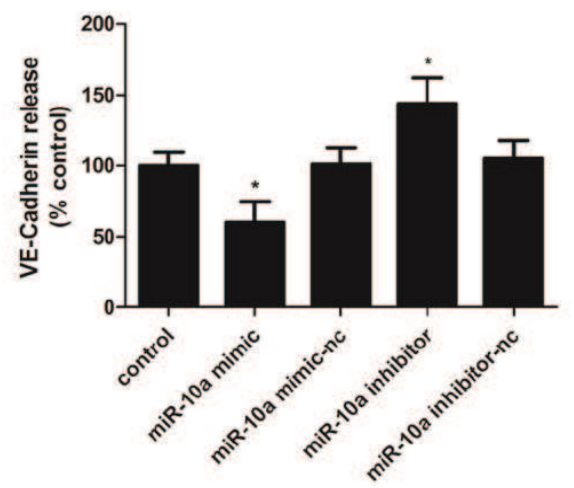

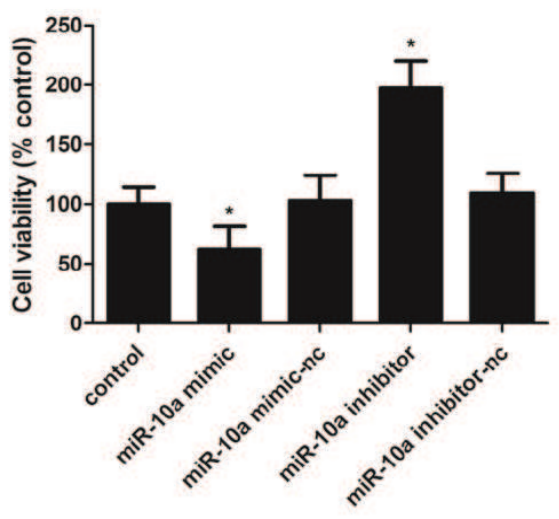

D
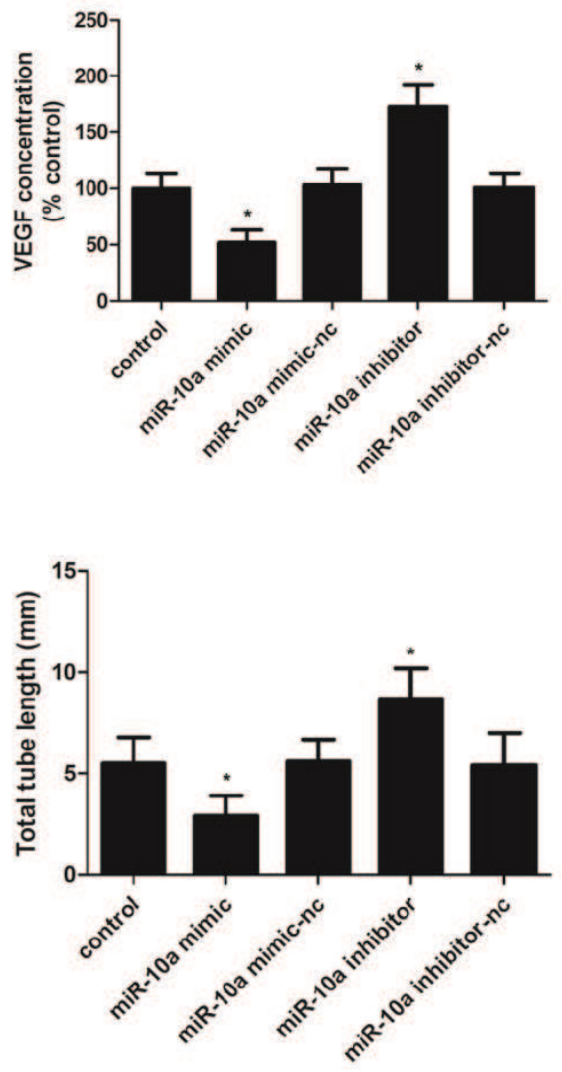

Fig. 2. MiR-10a suppresses MUVECs' viability, migration and tube formation in vitro. MiR-10a levels in MUVECs was analyzed by using RT-PCR after transfection with miR-10a mimic or inhibitor or mimic/inhibitor-negative control (nc) for $48 \mathrm{~h}$. U6 was used as a loading control (A). Cell viability was assessed by MTT (B). MUVECs' migration was confirmed via a transwell assay (C). An ELISA assay was used to test VEGF (D) and VE-cadherin (E) concentrations in the culture medium. The matrigel tube formation assay was performed to analyze the ability of MUVECs to integrate into the vascular structure (F). The * symbol indicates differences from their respective controls, at $\mathrm{p}<0.01$ and $\mathrm{p}<0.05$, respectively.

observing cell viability, migration, release of VEGF, VE-Cadherin and tube formation. RTPCR analysis showed a nearly 3-fold increase of mature miR-10a expression after miR-10a mimic transfection, as well as a 3-fold decrease after transfection of miR-10a inhibitor in 


\section{Cellular Physiology Cell Physiol Biochem 2015;37:2194-2208 \begin{tabular}{ll|l} 
DOI: 10.1159/000438576 & () 2015 The Author(s). Published by S. Karger AG, Basel
\end{tabular}

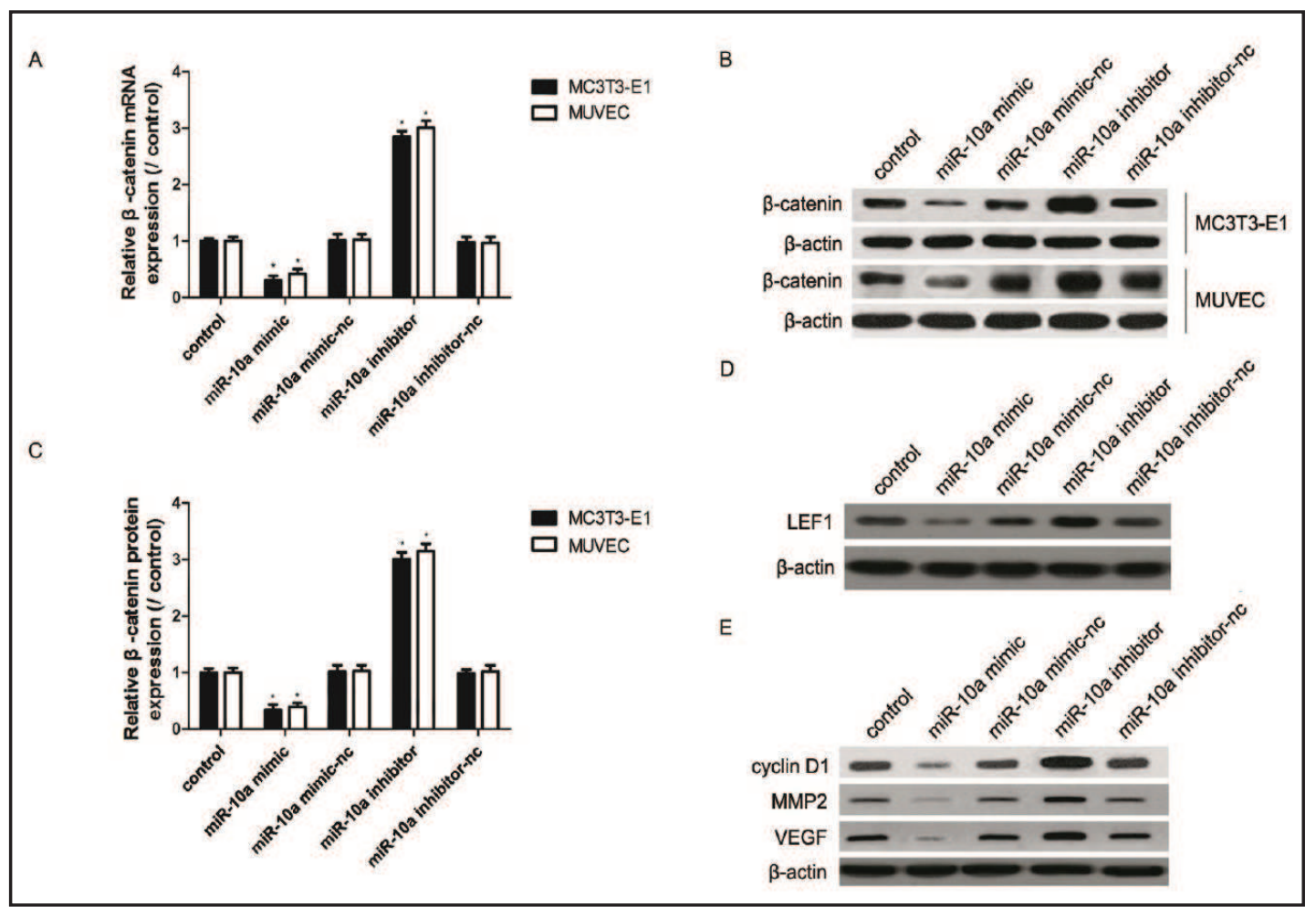

Fig. 3. MiR-10a triggered the activation of the Wnt signaling pathway. After pretreatment with the miR10a mimic or inhibitor or mimic/inhibitor-negative control (nc), the $\beta$-catenin mRNA expression of both MC3T3-E1 cells and MUVECs were assessed using RT-PCR (A), and the corresponding protein levels were determined using Western blot (B) and were quantized (C). The protein expression of key osteogenic-specific genes, LEF1 (D), and angiogenesis related genes, cyclin D1, MMP2, and VEGF (E), were also analyzed. Data are presented as mean \pm SD. The symbol * indicates differences from the controls, at $\mathrm{p}<0.05$.

MUVECs (Fig. 2A). The results of the MTT assay exhibited an approximate $40 \%$ decrease in cell viability after miR-10a mimic transfection, but a 2-fold increase in MUVEC viability after miR-10a inhibitor transfection compared to the controls (Fig. 2B).

We further analyzed whether miR-10a could influence the chemo taxis of MUVECs using a transwell migration assay. As shown in Fig. 2C, miR-9 mimic pretreatment induced about a $50 \%$ decrease in cell migration compared to the controls. In contrast, transfection of miR-10a inhibitor induced a 2-fold increase in MUVEC migration. The results suggested that miR-10a overexpression effectively suppressed the MUVECs migration, impeding angiogenesis, while the silence of miR-10a might have facilitated angiogenesis. VEGF and VE-cadherin are known to be the key elements of angiogenesis. An ELISA assay confirmed the significant decrease in both VEGF and VE-cadherin levels in the culture medium after pretreatment with a miR-10a mimic. In contrast, transfection of the miR-10a inhibitor reduced the concentrations of VEGF and VE-cadherin (Fig. 2D and E). Further tube formation assays suggested that pre-miR-10a treatment significantly decreased the total tube length, while the miR-10a silence effectively promoted a total tube length in vitro compared with the controls (Fig. 2F), implying that miR-10a was associated with angiogenesis.

MiR-10a down-regulates $\beta$-catenin expression in both transcription and protein levels

The Wnt/ $\beta$-catenin signaling pathway was found to play an important role in cell proliferation, differentiation and bone regeneration. To further explore the mechanism involved in miR-10a-regulated osteoblast differentiation and angiogenesis, we analyzed the $\beta$-catenin expression in both the mRNA and protein levels via RT-PCR and Western blotting. 


\section{Cellular Physiology Cell Physiol Biochem 2015;37:2194-2208 and Biochemistry Published online: November 27, 2015 (2015w.karger.com/cpb \\ Li et al.: MicroRNA-10a Regulates Osteoblast Differentiation and Angiogenesis}

The results showed that miR-10a overexpression decreased the $\beta$-catenin mRNA expression of MC3T3-E1 cells; meanwhile, elevated $\beta$-catenin levels were observed by miR-10a inhibition. Furthermore, the protein expression of $\beta$-catenin was also markedly decreased after miR-10a pre-treatment and was increased by miR-10a inhibition. The same effect was observed in the MUVECs, as expected. The miR-10a overexpression significantly down-regulated both the $\beta$-catenin mRNA expression and its protein level (Fig. 3A, B and C). The protein expression of key osteogenic-specific gene LEF1, as well as angiogenesis-related genes, cyclin D1, MMP2, VEGF, which are downstream molecules of the Wnt signaling pathway, was also detected. As expected, miR-10a overexpression significantly brought down the protein level of LEF1 in MC3T3-E1 cells (Fig. 3D). Meanwhile, the inhibitory effect on cyclin D1, MMP2, and VEGF expression triggered by miR-10a overexpression was also determined in the miR-10a mimic groups (Fig. 3E). In contrast, transfection of the miR-10a inhibitor effectively up-regulated the expression of those proteins underlying the Wnt/ $\beta$-catenin signaling pathway. These results suggested that the miR-10a might trigger osteoblast differentiation and angiogenesis by regulating $\beta$-catenin expression.

MiR-10a regulated osteoblastic differentiation and angiogenesis by regulating $\beta$-catenin expression

To further delineate the effect of the Wnt/ $\beta$-catenin signaling pathway on miR-10atrigged osteoblast differentiation and pro angiogenic activity, the Wnt inhibitor Licl was used. RT-PCR analysis revealed that miR-10a overexpression down-regulated $\beta$-catenin mRNA expression in both MC3T3-E1 and MUVECs cell lines, while this suppressing effect was markedly impeded after Licl pretreatment (Fig. 4A). The same effects can be seen in the protein expression of $\beta$-catenin assessed by Western blot (Fig. 4B and C). Furthermore, the down-regulation of ALP, Runx2, and Osx, as well as OC and DLX5, mRNA induced by miR-10a mimic in MC3T3-E1 cells was also reversed when pretreatment by Licl (Fig. 4D and E). Moreover, the decrease in MUVECs' viability (Fig. 4F) and migration (Fig. 4G) induced by miR-10a up-regulation was also dramatically attenuated following Licl stimulation. Importantly, Licl treatment also blocked miR-10a-induced suppression of tube formation (Fig. 4H). Interestingly, when pretreatment control cells with LiCl in the absence of miR-10a mimic transfection, the $\beta$-catenin protein expression, as well as ALP, Runx2, Osx, OC, DLX5 mRNA levels, and cell migration, tube formation has been significantly increased compare with the control group. Moreover, as LiCI is not very specific and also Gsk3- $\beta$ has many other targets [20]. Therefore, all these results were confirmed by Gsk3- $\beta$ knock down and also $\beta$-catenin overexpression. And $\mathrm{LiCl}$ as well as $\beta$-catenin overexpression has also been used to investigate whether miR-10a can still suppress osteoblast differentiation in the presence of Wnt activation. Results in Fig. 5 showed that in the presence of Wnt activation miR-10a can partially suppress osteoblast differentiation. These results indicate that miR-10a may suppress osteoblastic differentiation and angiogenesis by regulating $\beta$-catenin expression.

\section{Discussion}

In the present study, we demonstrated a negative role of miR-10a during osteoblast differentiation and angiogenesis in vitro. First, we provided evidence that miR-10a expression was decreased during the BMP2-induced osteoblast differentiation. Further analysis demonstrated that overexpression of miR-10a inhibited MC3T3-E1 cell differentiation into osteoblasts and pro angiogenic activity in MUVECs, while miR-10a silence promoted the process of osteoblast differentiation and pro angiogenic activity. The mechanism assay confirmed that miR-10a regulated osteoblast differentiation and pro angiogenic activity by regulating $\beta$-catenin expression. These findings suggest a potential important role of miR$10 \mathrm{a}$ in regulating the process of bone regeneration.

Recently, miRNAs have been shown to be involved in the regulation of cellular behaviors, including differentiation and development, metabolism, proliferation, apoptosis, viral 


\section{Cellular Physiology Cell Physiol Biochem 2015;37:2194-2208 \begin{tabular}{ll|l} 
DOI: 10.1159/000438576 & $\begin{array}{l}\text { O 2015 The Author(s). Published by S. Karger AG, Basel } \\
\text { www.karger.com/cpb }\end{array}$ \\
\hline
\end{tabular}

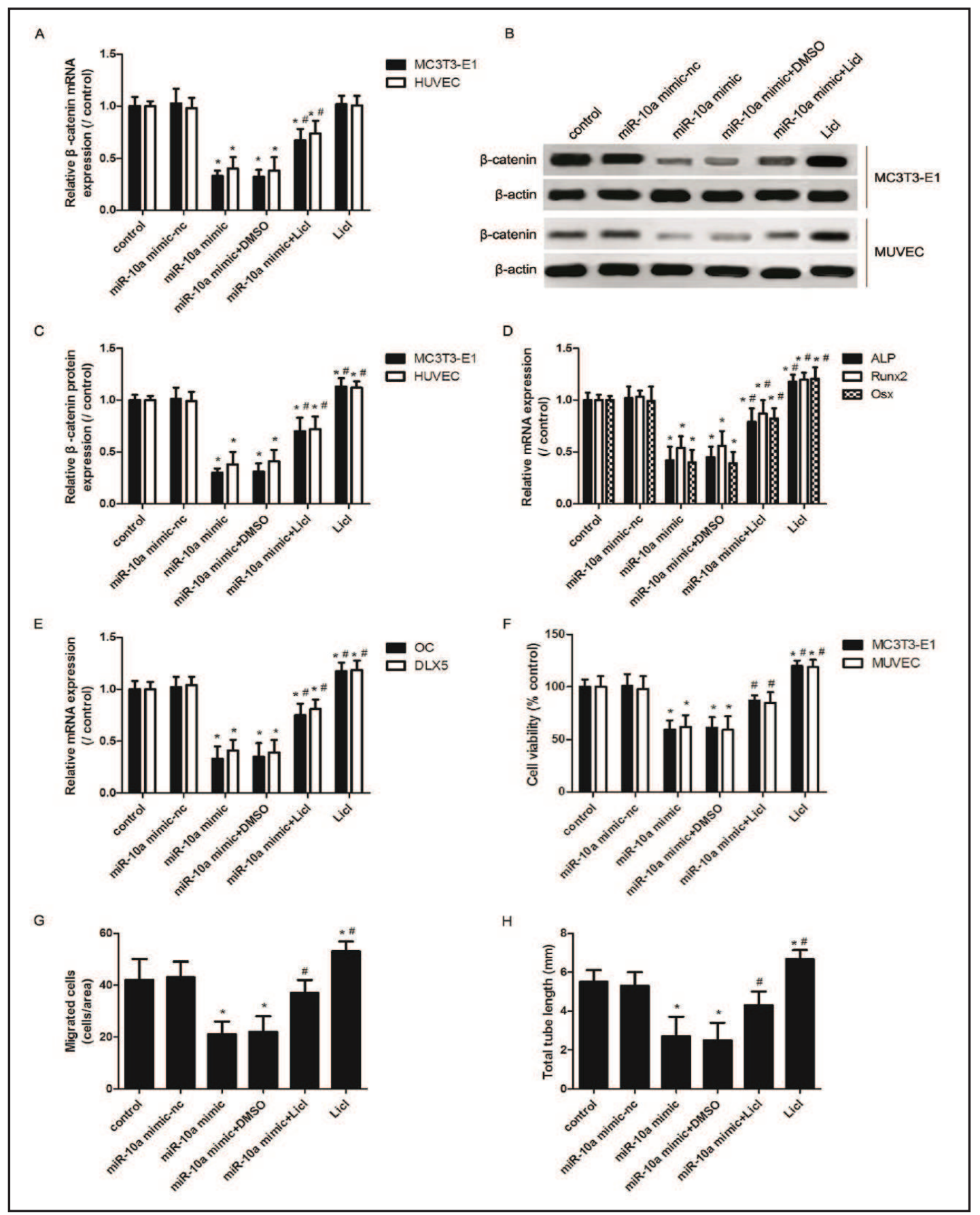

Fig. 4. MiR-10a inhibited osteoblastic differentiation and angiogenesis by regulating $\beta$-catenin expression. After pretreatment of MC3T3-E1 cells and MUVECs with LiCl for $48 \mathrm{~h}$, the mRNA expression of $\beta$-catenin was analyzed using RT-PCR (A). Corresponding protein levels were analyzed by Western blotting (B) and were quantized (C). The protein levels of ALP, Runx2, Osx (D), and OC, DLX5 (E) in MC3T3-E1 cells, as well as cell viability $(F)$, migration $(G)$ and tube formation $(H)$ of MUVECs, were also assessed. $\beta$-actin served as the loading control. The results are presented as mean \pm SD. The symbol * indicates differences from their respective controls, at $\mathrm{p}<0.05$. The symbol \# indicates differences from the miR-10a mimic group, at $\mathrm{p}<0.05$.

infection and tumor genesis [21,22], and dysregulation of miRNAs can result in a myriad of pathological states [23]. Recently, dozens of miRNAs are emerging as important negative 


\section{\begin{tabular}{ll} 
Cellular Physiology & Cell Physiol Biochem 2015;37:2194-2208 \\
\cline { 2 - 3 } DOI: 10.1159/000438576 & O 2015 The Author(s). Published by S. Karger AG, Basel
\end{tabular} and Biochemistry Published online: November 27, 2015 www.karger.com/cpb

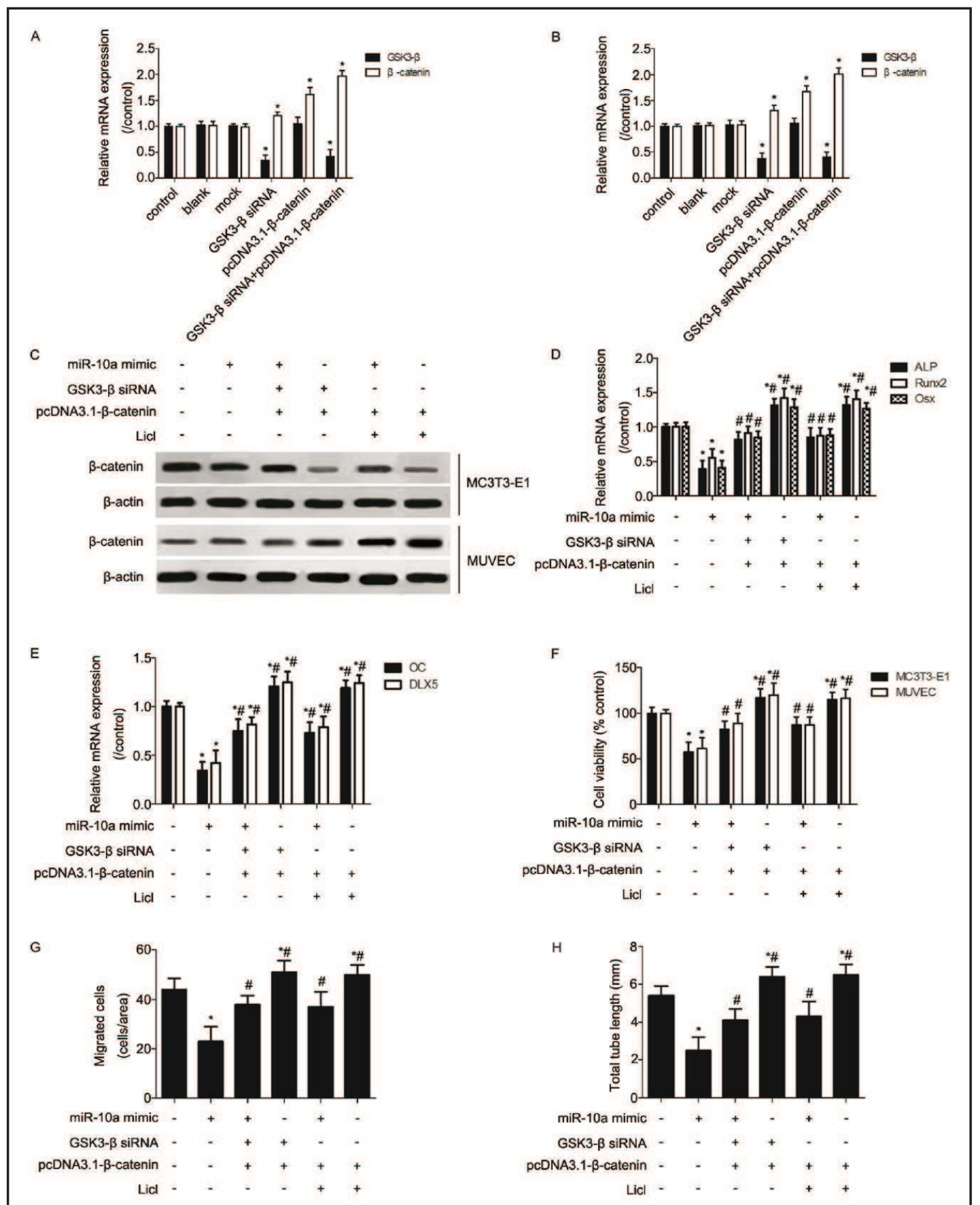

Fig. 5. $\beta$-catenin was involved in miR-10a induced osteoblastic differentiation and angiogenesis suppression After pretreatment of MC3T3-E1 cells (A) and MUVECs (B) with GSK3- $\beta$ siRNA and/or pcDNA3.1- $\beta$-catenin for $48 \mathrm{~h}$, the mRNA expression of GSK3- $\beta$ and $\beta$-catenin was analyzed using RT-PCR. Corresponding protein levels were analyzed by Western blotting (C). The protein levels of ALP, Runx2, Osx (D), and OC, DLX5 (E) in MC3T3-E1 cells, as well as cell viability (F), migration (G) and tube formation (H) of MUVECs, were also assessed. $\beta$-actin served as the loading control. The results are presented as mean \pm SD. The symbol * indicates differences from their respective controls, at $\mathrm{p}<0.05$. The symbol \# indicates differences from the miR-10a mimic group, at $\mathrm{p}<0.05$.

or positive regulators of posttranscriptional gene expression and are considered critical for osteogenesis [24,25]. Among of them, miR-10a has recently been involved in the progression 


\section{Cellular Physiology Cell Physiol Biochem 2015;37:2194-2208

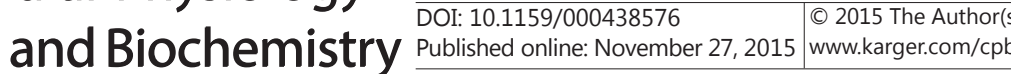 \\ Li et al.: MicroRNA-10a Regulates Osteoblast Differentiation and Angiogenesis}

of several diseases, such as kidney or cardiac injury $[18,26]$. Reports show that miR-10a is up-regulated in NSCLC and may promote cancer by targeting PTEN [27]. MiR-10a also targets Bcl-6 and constrains the plasticity of helper T cells [28]. In addition, studies have shown that miR-10a can suppress angiogenesis in tumor tissues [29]. During the process of bone regeneration, osteoblastic differentiation and angiogenesis are both key elements, and thus, we explored the effects of miR-10a in bone regeneration.

In our study, miR-10a expression was significantly decreased in the process of BMP2induced osteoblastic differentiation, which is consistent with the previous study [30]. In the process of bone regeneration, ALP activity and calcification level are considered to be markers of osteogenic lineage differentiation. In this study, after miR-10a mimic transfection, ALP staining indicated a down-regulated osteoblast phenotype, and ARS staining confirmed a reduction of calcification in MC3T3-E1 cells. In contrast, transfection of the miR-10a inhibitor reversed those above-mentioned results. The transcription factors Runx2 and Osx are crucial early markers of osteogenic lineage. OC is a major component of the bone extracellular matrix synthesized exclusively by osteoblastic cells [31] and DLX5 acts as the early BMP-responsive transcriptional activator needed for osteoblast differentiation [32]. In the current study, miR-10a overexpression effectively brings down the mRNA levels of ALP, Runx2, OSX, OC, and DLX5, while the silence of miR-10a up-regulated the expression of those osteogenic related genes. All of those results show that miR-10a may inhibit bone regeneration by suppressing osteoblast differentiation.

Angiogenesis is a key component of bone regeneration or repair. New blood vessels bring oxygen and nutrients to the highly metabolically active regenerating callus and serve as a route for bone precursor cells to reach the injury site. A variety of studies in transgenic and gene-targeted mice have demonstrated the importance of angiogenesis in fracture healing [33]. Proliferation and migration of MUVECs are closely related to angiogenesis. To clarify miR-10a function during bone regeneration, its role in angiogenesis was then investigated. Our data revealed that overexpression of miR-10a inhibited the cell viability of MUVECs, whereas inhibition of the miR-10a function enhanced the MUVECs' viability. Simultaneously, the migration capability of MUVECs, which was considered to be an important characterization for angiogenesis, was also decreased by miR-10a mimic transfection and increased by miR10 a inhibitor pretreatment.

Angiogenesis is regulated by a variety of growth factors, such as vascular endothelial growth factor (VEGF) and vascular endothelial cadherin (VE-cadherin) [34]. In this study, overexpression of miR-10a effectively decreased VEGF and VE-cadherin concentrations in the culture medium, while miR-10a silence increased both VEGF and VE-cadherin levels, suggesting that miR-10a might suppress angiogenesis. Tube formation plays an important role in angiogenesis. Studies have shown that inducing apoptosis in tube-forming endothelial cells can effectively suppress angiogenesis [35]. Just as expected, further analysis of tube formation ability showed a notable decrease in the formation of capillary tubes after miR10 a mimic preconditioning, but an obvious increase after miR-10a inhibitor transfection was also found. Together, these results indicate that miR-10a might play a negative role in bone regeneration based on the inhibition effects of angiogenesis.

In terms of skeletal homeostasis and bone repair, the Wnt/ $\beta$-catenin pathway is among the most attractive targets for such therapeutic intervention. Studies found that the activating mutations of the Wnt function in humans caused high bone mass phenotypes, such as van Buchem disease, whereas inactivating mutations caused osteopenic diseases, such as osteoporosis pseudoglioma syndrome [36]. These findings raise the possibility that modulation of the Wnt pathway is a viable path for improving bone formation. More importantly, the Wnt signaling in endothelial cells accounts for the regulation of angiogenesis in vitro [37]. In the current study, we found that miR-10a suppressed the Wnt/ $\beta$-catenin signaling pathway by decreasing $\beta$-catenin expression. Here, interestingly, we found miR-10a not only decreased the protein expression of $\beta$-catenin but also effecting its transcription. As one previous study show that down-regulated STAT3 expression can resulted in reduced $\beta$-catenin mRNA and protein levels [38], and another study reported that BAMBI knockdown 


\section{Cellular Physiology Cell Physiol Biochem 2015;37:2194-2208 \begin{tabular}{ll|l} 
and Biochemistry & Dublished online: November 27, 2015 & $\begin{array}{l}\text { O } 2015 \text { The Author(s). Published by S. Karger AG, Basel } \\
\text { wwer.com/cpb }\end{array}$ \\
\cline { 2 - 3 } &
\end{tabular} \\ Li et al.: MicroRNA-10a Regulates Osteoblast Differentiation and Angiogenesis}

can significantly decrease the expression of $\beta$-catenin mRNA and suppress metastasis of gastric cancer cells [39]. However, miR-10a silencing may reverses cisplatin resistance in human lung cancer cell line via the TGF- $\beta /$ Smad2/STAT3/STAT5 pathway [40]. Thus, we speculate that miR-10a may indirectly affect the $\beta$-catenin mRNA expression by targeting STAT3 and/or BAMBI, and this will be further investigate in our future research. We also observed that $\mathrm{LiCl}$ with miR-10a mimic pretreatment bring up the mRNA expression of $\beta$-catenin compare with the miR-10a mimic group, but there was no statistical difference between the cells only treated with $\mathrm{LiCl}$ and controls. We speculate that $\mathrm{LiCl}$ as a metal ion preparations, may effecting the transfection efficiency or function realization of the miR-10a mimic.

LEF1 was reported to promote osteoblast differentiation, cyclinD1 focused on cell proliferation, MMP2 was effectively associated with cell migration, and VEGF was one of the key elements for vascular formation. To further analyze the role of Wnt/ $\beta$-catenin in miR10 a induced pro-differentiation and angiogenesis, we analyzed the expression of osteogenicrelated protein LEF1, and angiogenesis-related protein cyclinD1, MMP2, and VEGF, which were located downstream of the Wnt/ $\beta$-catenin signaling pathway. As expected, miR-10a mimic transfection significantly down-regulated the protein levels of LEF1, cyclinD1, MMP2, and VEGF, while miR-10a inhibitor reversed these results. Then, we inhibited the signaling by using the Wnt signaling activator, Licl. The results showed that pretreatment with Licl effectively attenuated the suppression effects of osteoblast differentiation in MC3T3-E1 cells that were induced by miR-10a overexpression. Consistently, Wnt activation also brings up the MUVECs' viability and migration, as well as tube formation, in vitro. All results above were further confirmed by Gsk3- $\beta$ knock down and also $\beta$-catenin overexpression. These results suggested that miR-10a might regulate osteoblast differentiation and angiogenesis by regulating $\beta$-catenin expression.

In summary, miR-10a was identified as a novel regulator in osteoblast differentiation and angiogenesis through regulating $\beta$-catenin expression in vitro. Therefore, this study may provide new insights into the possibility of miR-10a and miR-10a being potential therapeutic targets in the management of bone regeneration-related diseases.

\section{Acknowledgments}

This work was supported by the Basic Research Grants of Shaanxi Province (No. 2014JM4197).

\section{Disclosure Statement}

The authors have declared that no competing interests exist.

\section{References}

1 Fang S, Deng Y, Gu P, Fan X: Micrornas regulate bone development and regeneration. Int J Mol Sci 2015;16:8227-8253.

2 Long F, Ornitz DM: Development of the endochondral skeleton. CSH Perspect Biol 2013;5:a008334.

3 Hu N, Jiang D, Huang E, Liu X, Li R, Liang X, Kim SH, Chen X, Gao JL, Zhang H, Zhang W, Kong YH, Zhang J, Wang J, Shui W, Luo X, Liu B, Cui J, Rogers MR, Shen J, Zhao C, Wang N, Wu N, Luu HH, Haydon RC, He TC, Huang W: Bmp9-regulated angiogenic signaling plays an important role in the osteogenic differentiation of mesenchymal progenitor cells. J Cell Sci 2013;126:532-541.

4 Wei J, Shi Y, Zheng L, Zhou B, Inose H, Wang J, Guo XE, Grosschedl R, Karsenty G: Mir-34s inhibit osteoblast proliferation and differentiation in the mouse by targeting satb2. J Cell Biol 2012;197:509-521. 


\section{Cellular Physiology Cell Physiol Biochem 2015;37:2194-2208 \begin{tabular}{l|l|l}
\cline { 2 - 2 } DOI: 10.1159/000438576 & ( ) 2015 The Author(s). Published by S. Karger AG, Basel
\end{tabular} and Biochemistry Published online: November 27, 2015 www.karger.com/cpb \\ Li et al.: MicroRNA-10a Regulates Osteoblast Differentiation and Angiogenesis}

5 Portal-Nunez S, Lozano D, Esbrit P: Role of angiogenesis on bone formation. Histol Histopathol 2012;27:559-566.

6 Silverio KG, Davidson KC, James RG, Adams AM, Foster BL, Nociti FH Jr, Somerman MJ, Moon RT: Wnt/betacatenin pathway regulates bone morphogenetic protein (bmp2)-mediated differentiation of dental follicle cells. J Periodontal Res 2012;47:309-319.

7 Bhattaram P, Penzo-Mendez A, Kato K, Bandyopadhyay K, Gadi A, Taketo MM, Lefebvre V: Soxc proteins amplify canonical wnt signaling to secure nonchondrocytic fates in skeletogenesis. J Cell Biol 2014;207:657-671.

8 Holland JD, Klaus A, Garratt AN, Birchmeier W: Wht signaling in stem and cancer stem cells. Curr Opin Cell Biol 2013;25:254-264.

9 Boonanantanasarn K, Lee HL, Baek K, Woo KM, Ryoo HM, Baek JH, Kim GS: Egf inhibits wnt/beta-catenininduced osteoblast differentiation by promoting beta-catenin degradation. J Cell Biochem 2015;116:28492857.

10 Huntzinger E, Izaurralde E: Gene silencing by micrornas: Contributions of translational repression and mrna decay. Nat Rev Genet 2011;12:99-110.

11 Qiao W, Chen L, Zhang M: Microrna-205 regulates the calcification and osteoblastic differentiation of vascular smooth muscle cells. Cell Physiol Biochem 2014;33:1945-1953.

12 Qi L, Zhang Y: The microrna 132 regulates fluid shear stress-induced differentiation in periodontal ligament cells through mtor signaling pathway. Cell Physiol Biochem 2014;33:433-445.

13 Laine SK, Alm JJ, Virtanen SP, Aro HT, Laitala-Leinonen TK: Micrornas mir-96, mir-124, and mir-199a regulate gene expression in human bone marrow-derived mesenchymal stem cells. J Cell Biochem 2012;113:2687-2695.

14 Itoh T, Ando M, Tsukamasa Y, Akao Y: Expression of bmp-2 and ets1 in bmp-2-stimulated mouse preosteoblast differentiation is regulated by microrna-370. FEBS Lett 2012;586:1693-1701.

15 Plummer PN, Freeman R, Taft RJ, Vider J, Sax M, Umer BA, Gao D, Johns C, Mattick JS, Wilton SD, Ferro V, McMillan NA, Swarbrick A, Mittal V, Mellick AS: Micrornas regulate tumor angiogenesis modulated by endothelial progenitor cells. Cancer Res 2013;73:341-352.

16 Hassel D, Cheng P, White MP, Ivey KN, Kroll J, Augustin HG, Katus HA, Stainier DY, Srivastava D: Microrna-10 regulates the angiogenic behavior of zebrafish and human endothelial cells by promoting vascular endothelial growth factor signaling. Circ Res 2012;111:1421-1433.

17 Wang N, Zhou Y, Jiang L, Li D, Yang J, Zhang C-Y, Zen K: Urinary microrna-10a and microrna-30d serve as novel, sensitive and specific biomarkers for kidney injury. PLoS One 2012;7:e51140.

18 Jamaluddin MS, Weakley SM, Zhang L, Kougias P, Lin PH, Yao Q, Chen C: Mirnas: Roles and clinical applications in vascular disease. Expert Rev Mol Diagn 2011;11:79-89.

19 Li H, Xie H, Liu W, Hu R, Huang B, Tan YF, Xu K, Sheng ZF, Zhou HD, Wu XP, Luo XH: A novel microrna targeting hdac5 regulates osteoblast differentiation in mice and contributes to primary osteoporosis in humans. J Clin Invest 2009;119:3666-3677.

20 McCubrey JA, Steelman LS, Bertrand FE, Davis NM, Abrams SL, Montalto G, D'Assoro AB, Libra M, Nicoletti F, Maestro R, Basecke J, Cocco L, Cervello M, Martelli AM: Multifaceted roles of gsk-3 and wnt/beta-catenin in hematopoiesis and leukemogenesis: Opportunities for therapeutic intervention. Leukemia 2014;28:15-33.

21 Huang Y, Shen XJ, Zou Q Wang SP, Tang SM, Zhang GZ: Biological functions of micrornas: A review. J Physiol Biochem 2011;67:129-139.

22 Jia HY, Chen F, Chen JZ, Wu SS, Wang J, Cao QY, Chen Z, Zhu HH: Microrna expression profiles related to early stage murine concanavalin a-induced hepatitis. Cell Physiol Biochem 2014;33:1933-1944.

23 Liu N, Jiang N, Guo R, Jiang W, He Q-M, Xu Y-F, Li Y-Q, Tang L-L, Mao Y-P, Sun Y: Mir-451 inhibits cell growth and invasion by targeting mif and is associated with survival in nasopharyngeal carcinoma. Mol Cancer 2013;12:123.

24 Khraiwesh B, Zhu JK, Zhu J: Role of mirnas and sirnas in biotic and abiotic stress responses of plants. BBA 2012;1819:137-148.

25 van Wijnen AJ, van de Peppel J, van Leeuwen JP, Lian JB, Stein GS, Westendorf JJ, Oursler MJ, Im HJ, Taipaleenmaki H, Hesse E, Riester S, Kakar S: Microrna functions in osteogenesis and dysfunctions in osteoporosis. Curr Osteoporosis Rep 2013;11:72-82.

26 Aguado-Fraile E, Ramos E, Conde E, Rodriguez M, Liano F, Garcia-Bermejo ML: Micrornas in the kidney: Novel biomarkers of acute kidney injury. Nefrologia 2013;33:826-834. 


\section{Cellular Physiology Cell Physiol Biochem 2015;37:2194-2208 \begin{tabular}{ll|l} 
10.1159/000438576 & ( ) 2015 The Author(s). Published by S. Karger AG, Basel
\end{tabular} and Biochemistry Published online: November 27, 2015 www.karger.com/cpb}

Li et al.: MicroRNA-10a Regulates Osteoblast Differentiation and Angiogenesis

27 Yu T, Liu L, Li J, Yan M, Lin H, Liu Y, Chu D, Tu H, Gu A, Yao M: Mirna-10a is upregulated in nsclc and may promote cancer by targeting pten. Oncotarget DOI: 10.18632/4972.

28 Takahashi H, Kanno T, Nakayamada S, Hirahara K, Sciume G, Muljo SA, Kuchen S, Casellas R, Wei L, Kanno Y, O'Shea JJ: Tgf-beta and retinoic acid induce the microrna mir-10a, which targets bcl- 6 and constrains the plasticity of helper t cells. Nat Immunol 2012;13:587-595.

29 Tang H: Mir-10a regulates epithelial-mesenchymal transition and adhesion and angiogenesis in hepatoma. FASEB J 2013;27:lb153.

30 Okamoto H, Matsumi Y, Hoshikawa Y, Takubo K, Ryoke K, Shiota G: Involvement of micrornas in regulation of osteoblastic differentiation in mouse induced pluripotent stem cells. PloS One 2012;7:e43800.

31 Chevallier N, Anagnostou F, Zilber S, Bodivit G, Maurin S, Barrault A, Bierling P, Hernigou P, Layrolle P, Rouard H: Osteoblastic differentiation of human mesenchymal stem cells with platelet lysate. Biomaterials 2010;31:270-278.

32 Singh M, Del Carpio-Cano FE, Monroy MA, Popoff SN, Safadi FF: Homeodomain transcription factors regulate bmp-2-induced osteoactivin transcription in osteoblasts. J Cell Physiol 2012;227:390-399.

33 Singh A, Ali S, Mahdi AA, Srivastava RN: Micrornas and their role in bone remodeling and pathogenesis. Brit J Med 2012;2:727-749.

34 Giannotta M, Trani M, Dejana E: Ve-cadherin and endothelial adherens junctions: Active guardians of vascular integrity. Dev Cell 2013;26:441-454.

35 Kunimasa K, Ahn M-R, Kobayashi T, Eguchi R, Kumazawa S, Fujimori Y, Nakano T, Nakayama T, Kaji K, Ohta T: Brazilian propolis suppresses angiogenesis by inducing apoptosis in tube-forming endothelial cells through inactivation of survival signal erk1/2. Evid-Based Compl Alt 2010;2011:870753.

36 Leucht P, Helms JA: Wnt signaling: An emerging target for bone regeneration. J Am Acad Orthop Sur 2015;23:67-68.

37 Newman AC, Hughes CC: Macrophages and angiogenesis: A role for wnt signaling. Vascular cell 2012;4:13.

38 Ibrahem S, Al-Ghamdi S, Baloch K, Muhammad B, Fadhil W, Jackson D, Nateri AS, Ilyas M: Stat3 paradoxically stimulates beta-catenin expression but inhibits beta-catenin function. Int J Exp Patho 2014;95:392-400.

39 Liu K, Song X, Ma H, Liu L, Wen X, Yu J, Wang L, Hu S: Knockdown of bambi inhibits beta-catenin and transforming growth factor beta to suppress metastasis of gastric cancer cells. Mol Med Rep 2014;10:874880.

40 Sun W, Ma Y, Chen P, Wang D: Microrna-10a silencing reverses cisplatin resistance in the a549/cisplatin human lung cancer cell line via the transforming growth factor-beta/smad2/stat3/stat5 pathway. Mol Med Rep 2015;11:3854-3859. 